\title{
Elderly Chinese Couples' Primary Room Use in Urban Apartments
}

\author{
Xiaoyu $\mathrm{Qu}^{* 1}$, Xinnan Zhang ${ }^{2}$, Daisuke Matsushita ${ }^{3}$ and Tetsu Yoshida ${ }^{4}$ \\ ${ }^{1}$ Architect, Architectural Design and Research Institute of Tsinghua University, China \\ ${ }^{2}$ Doctoral Candidate, Graduate School of Engineering, Kyoto University, Japan \\ ${ }^{3}$ Associate Professor, Department of Architecture, Okayama University of Science, Japan \\ ${ }^{4}$ Associate Professor, Graduate School of Engineering, Kyoto University, Japan
}

\begin{abstract}
This study aimed to clarify room use in the dwelling units of elderly Chinese couples in their daily lives. For this purpose, the authors used Active Radio Frequency Identification technology (Active RFID) to identify the room (Base) in which elderly Chinese couples stay for the longest duration between rising and going to bed. Findings showed that the surveyed couples could be classified into two types: i.) Those who use and share the bedroom as Base, and ii.) Those who use the living room as a shared Base in the evening and tend to use different rooms as Base during the day. Most elderly men stayed in the same Base during the day, while the elderly women used multiple rooms in the morning. The Base obtained by objective observation (Objective Base) and the Base identified by subjects (Subjective Base) were more in accord during the day. This shows that the Base in the mind of the subjects indicated the room where they spent the most time during the day. In summer, they also chose a north-facing or windowless room as Base. Additional interviews revealed that this choice was made because such rooms were cooler.
\end{abstract}

Keywords: elderly couple; room use; base; dwelling unit; Active RFID

\section{Introduction}

The Chinese government's one-child policy has produced millions of families composed of a couple and one child. When the child leaves the household, the elderly ${ }^{1}$ couple may continue to live by themselves for many years. Therefore, the living status of elderly couples has drawn increasing attention. Compared with the working young, the elderly spend more time in the house. Left to their own devices, safe, comfortable, and convenient houses have become a bigger priority for this population. Although attention has been paid to the construction of safe, barrier-free facilities in houses, few studies focus on the layout of rooms based on measuring their actual room use.

Moreover, in 2006, a policy was enacted stating that the total construction area of dwelling units with an area less than $90 \mathrm{~m}^{2}$ per unit (with usable living space at about $70 \mathrm{~m}^{2}$ ) should cover $70 \%$ of the total construction area of the urban residential quarter ${ }^{2}$. According to this policy, the total area of a new unit will shrink, and compared with an old regular unit, about $10 \mathrm{~m}^{2}$ of the living space will be lost. Therefore,

*Contact Author: Xiaoyu Qu, Architect, Architectural Design and Research Institute of Tsinghua University,

Beijing, 100084 China

Tel: +86-10-62773086 Fax: +86-10-62773086

E-mail:w4wind@163.com

(Received April 8, 2009 ; accepted May 17, 2010) either the area per room or the number of rooms must be adjusted in the new construction, and research is essential to evaluate which approach is best.

This presents a design challenge for building dwelling spaces for elderly Chinese couples. A detailed understanding of the room use is needed among this population, which would form a basis for offering spatial conditions that can satisfy their needs within the limitation imposed by the policy.

The elderly have been observed to more frequently use certain room(s) in a house. Such room(s) are used for not only their daily routine activities but also for relaxation (Kataoka et al., 1994). Therefore, it is necessary to identify which room serves as the primary room for elderly couples and how they use it. Detailed knowledge about primary room use among this population will provide a basis for improving layout design in terms of room size, orientation of living space, and distance between rooms.

In this study, the authors aim to precisely clarify the primary room use of elderly Chinese couples. In order to clarify the factors of room use, the authors focused on the duration of the couple's stay in the rooms and recorded it by a method called active radio frequency identification technology (Active RFID).

\section{Previous Studies}

Some studies have focused on the primary room/ space used by an elderly person living alone. Koga and Takahashi (1997) interviewed single elderly people 
living alone and found that they paid attention to the connection between external space and the living space usually occupied by them. Masunaga, et al. (2002) found that single elderly persons tended to use one room with the best physical conditions, such as size, lighting, and storage space.

There are also studies on which room forms the primary room for families with elderly members. Kataoka, et al. (1994) used questionnaires and interviews to verify that elderly family members were aware of primary rooms, which tended to be the living room in the countryside and the bedroom in the city. Cao, et al. (1996) interviewed 24 families with elderly members in Tianjin and found that the elderly usually stayed in their own bedrooms. Sawada (2001) found that the elderly tended to eat and relax in a south-facing living room but slept separately in Japanese-style rooms. Nakazono, et al. (2006) found that in dwelling units with two rooms, the elderly tended to install tall furniture - such as wardrobes-in the smaller room and used the larger room for main living activities, such as dining and relaxing. Lin et al. (2006) found that the elderly Chinese in Dalian and Harbin used the same primary room during the day when they slept in the same room and separate primary rooms when they slept separately.

Although many factors regarding the room use of single elderly people and families with elderly members have been identified, the room use of elderly couples living alone has not been clarified. More details about the primary room(s) they use, including information about the variation and duration of such use during a day in which they stay for the longest period, such as the variation of the primary room in a day has not been precisely measured. However, it is difficult to measure the exact correspondence between time and room use through questionnaires and interviews because such methods are limited by the respondent's memory.

Since video cameras can hardly be used in real houses, a common method for quantitatively measuring living space use is a time allocation survey of living activities, in which participants record their schedules of room use for one or two days, including time, room, and activity. However, Sawachi and Matsuo (1989), who also used this method, pointed out that it suffers from one limitation: the difficulty of proving the conformity between the obtained data and the actual situation.

The development of sensing technology shows potential for the objective observation of living behaviors. There have been studies on (a) outdoor trajectories in living quarters using GPS (Li et al., 2008), (b) activity recognition in the house by statechange sensors (Matsuoka, 2002; Mori, 2005; Tapia et al., 2004), and (c) proving the accuracy of the RFID device (Enta, et al., 2008). However, the authors are unaware of research measuring room-use behavior of elderly couples in multiple, non-laboratory home environments.

Unlike studies by questionnaires and interviews that focus on statistically measuring the tendencies of large samples, this study focused on six cases. This is a small sample, but for each case, when and in which room the subjects were staying was recorded objectively and continuously for three to four days without overly burdening the subjects by using Active RFID. The use of a certain room was quantified by the duration of the subject's stay (staying duration) in that room. Before this study started, Active RFID was used to measure room use and time of use for a single elderly woman for eight successive days (Qu et al., 2008) and the validity of the method was proved. Next, the method was applied to clarify the room use of elderly Chinese couples.

\section{Purpose}

This study aimed to clarify the primary room use of elderly Chinese couples living in urban dwelling units. Our approach was to attempt to identify the room in which elderly Chinese couples stay for the longest duration between rising in the morning and going to bed at night (defined as "Base") on the basis of a continuous recording of their duration of stay in all the rooms. The authors were interested in the following questions:

1) Which room serves as the Base for elderly Chinese couples?

2) Is Base choice gender-related? According to previous research, room use differs by gender ${ }^{6}$. The authors wanted to measure any such differences in Base choice.

3) Is the Base identified by objective observation the same as the Base identified by the elderly couples themselves?

4) If the couples have a common Base, do they share the room or use it alone?

\section{Methods}

\subsection{Sensing device \\ 1) Active RFID system}

The components of the Active RFID system were as follows:

(1) Active RFID Tag (Tag)

(2) Active RFID Reader (Reader)

(3) PC (platform)

(4) Wireless Ethernet Converter (Converter)

The tag sent a signal with a unique ID on a persecond basis. Each reader was assigned a Static IP and installed in each room of the dwelling unit. The converter connected the $\mathrm{PC}$ and readers through a wireless LAN. The PC recorded the IP of the reader that had received signals from the tag, providing a continuous flow of data about when and in which room the subject was present. (Fig.1.) 


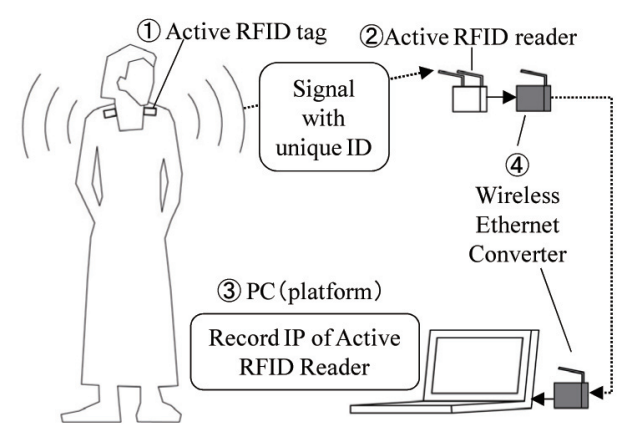

Fig.1. Composition of Active RFID System

\section{2) Acceleration sensor}

In order to fill in the missing values in the Active RFID data, the authors also used an acceleration sensor that helped judging whether the subject had moved. Fig.2. shows the configuration of the device.

\subsection{Investigation subjects and period}

The investigation was conducted in Tangshan ${ }^{3}$ and Beijing, two large cities in Northern China. Six elderly couples, all over the age of 60 , healthy, and living by themselves were chosen as the subjects (Fig.3.).

Each surveyed room was named on the basis of the subjects' description of its main function. Residents received visitors, watched $\mathrm{TV}$, and relaxed in the living room. The dining room was the room where residents daily ate dinner by themselves or with guests. For most couples, bedroom 1 was the room where the couple slept at night, and bedroom 2 was a guest room.

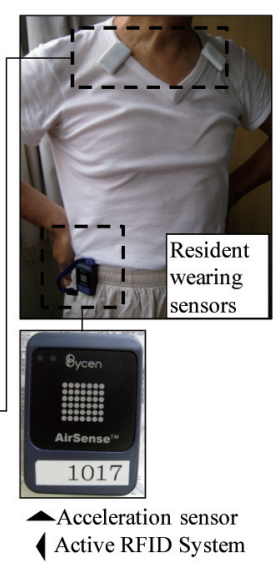

Fig.2. Configuration of Device

Couple C, however, slept in separate bedrooms. The studio was the room equipped with a bookshelf or PC, where the residents might read, nap, or perform other activities. The toilet was the room with a close stool, washbasin, and shower nozzle. Some residents also had a washer and made it a room for housework.

\subsection{Investigation flow}

1) The aforementioned readers were installed in every room of the dwelling unit.

2) The investigators wore the tags, moved among the rooms, and adjusted the parameters of the devices to ensure that the devices correctly recorded when and in which room the tag was.

3) Investigator instructed the residents on when and how to wear the tags and acceleration sensors.

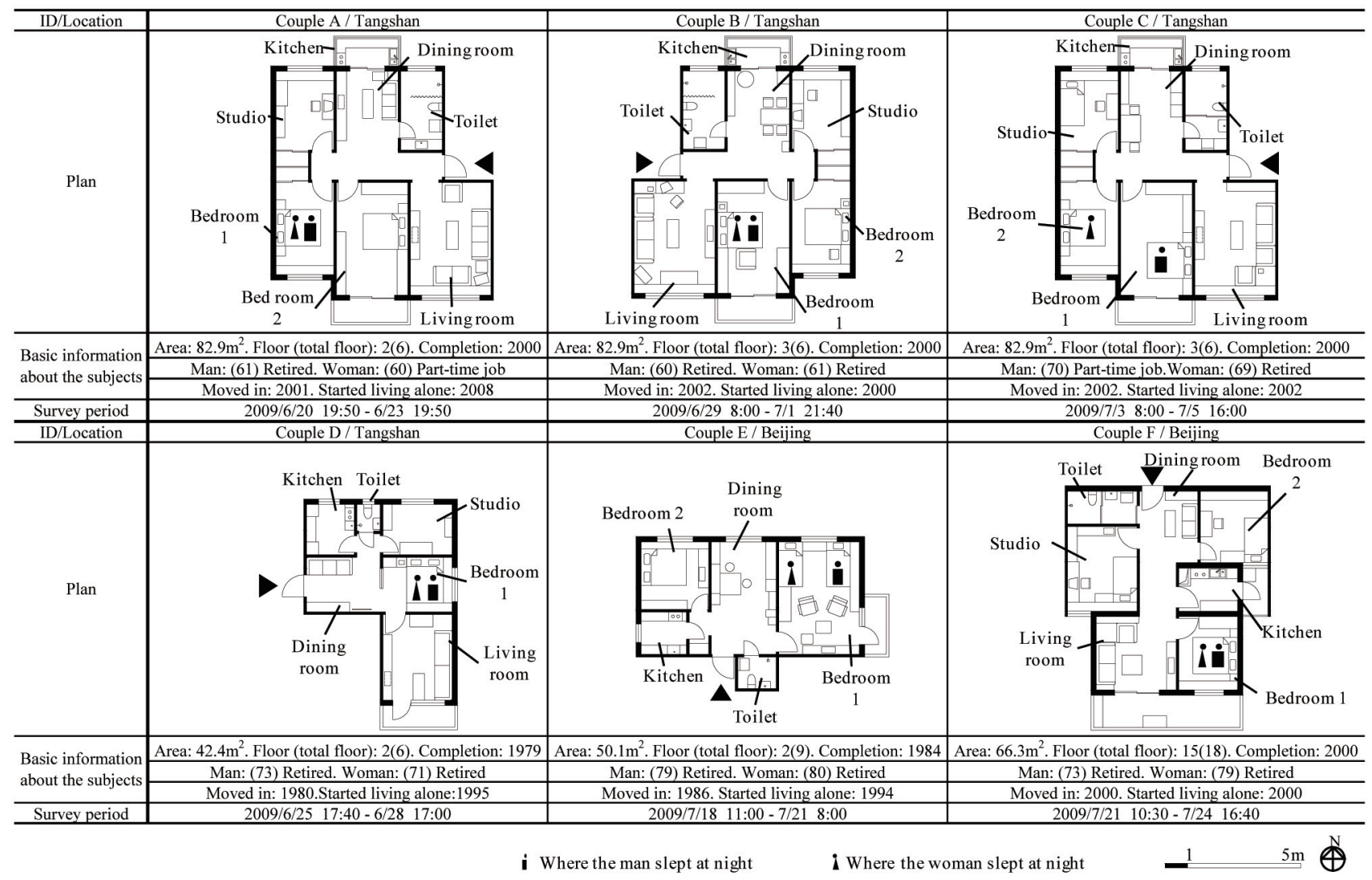

Fig.3. Basic Information about the Elderly Couples Surveyed 
4) The investigation started after the investigators left. The residents wore the tags and acceleration sensors between rising and going to bed when inside the house. They also recorded when and why they took off the device (going out, having a shower, and so on).

5) The investigation lasted three to four days and ended with the investigator's retrieval of the devices. A short interview was conducted. Each subject was asked to recall, from memory, which room or rooms he/she stayed in for the longest duration.

\subsection{Data correction}

According to the specific location of the resident, the reader in the adjacent room might receive signals sporadically, which the authors regarded as noise. For noise reduction, RFID data was filtered every minute. The number of signals received by each reader in a minute was counted, and the room in which the reader received the most signals in a minute was specified as the resident's "staying room" for that minute (Fig.4.). In this paper, "staying" in a certain room does not imply that the resident was absolutely stable in the room but that the resident was regarded to be inside the room in a particular minute. The "staying duration" in a certain room was the total number of minutes during the period from when the resident moved to the room until he/she moved to another room. Since all subjects
Before corrected

\begin{tabular}{|c|c|c|c|c|c|}
\hline \multirow[b]{2}{*}{ Time } & \multicolumn{3}{|c|}{$\begin{array}{l}\text { Number of received signals from } \\
\text { Active RFID Reader in each room }\end{array}$} & \multicolumn{2}{|c|}{ After corrected } \\
\hline & Living room & Kitchen & Dining room & Time & Staying room \\
\hline $8: 28: 00$ & 1 & 3 & 50 & $8: 28: 00$ & Dining room \\
\hline $8: 29: 00$ & & 45 & 4 & 8:29:00 & Kitchen \\
\hline
\end{tabular}

Fig.4. Example of Correction of Data

were healthy, it only took them a few seconds to move from one room to another, and so this duration was not counted.

\section{Results}

\subsection{Staying sequence}

After data correction ${ }^{4}$, the staying sequence showing when and in which room the subjects were staying could be expressed as illustrated in Fig.5. The following analysis is based on the staying sequence data.

\subsection{Base of each subject in each period 1) Obtaining of Base}

In order to clarify the variation in the total staying duration in a day, one day was divided into morning (time of rising until 12:00), afternoon (12:00-19:00), and evening (19:00-going to bed).

In order to obtain the Base, the proportion of the total staying duration of a given subject in a given room in a given period ( $\mathrm{T}$ ) and in the whole day (Sum)

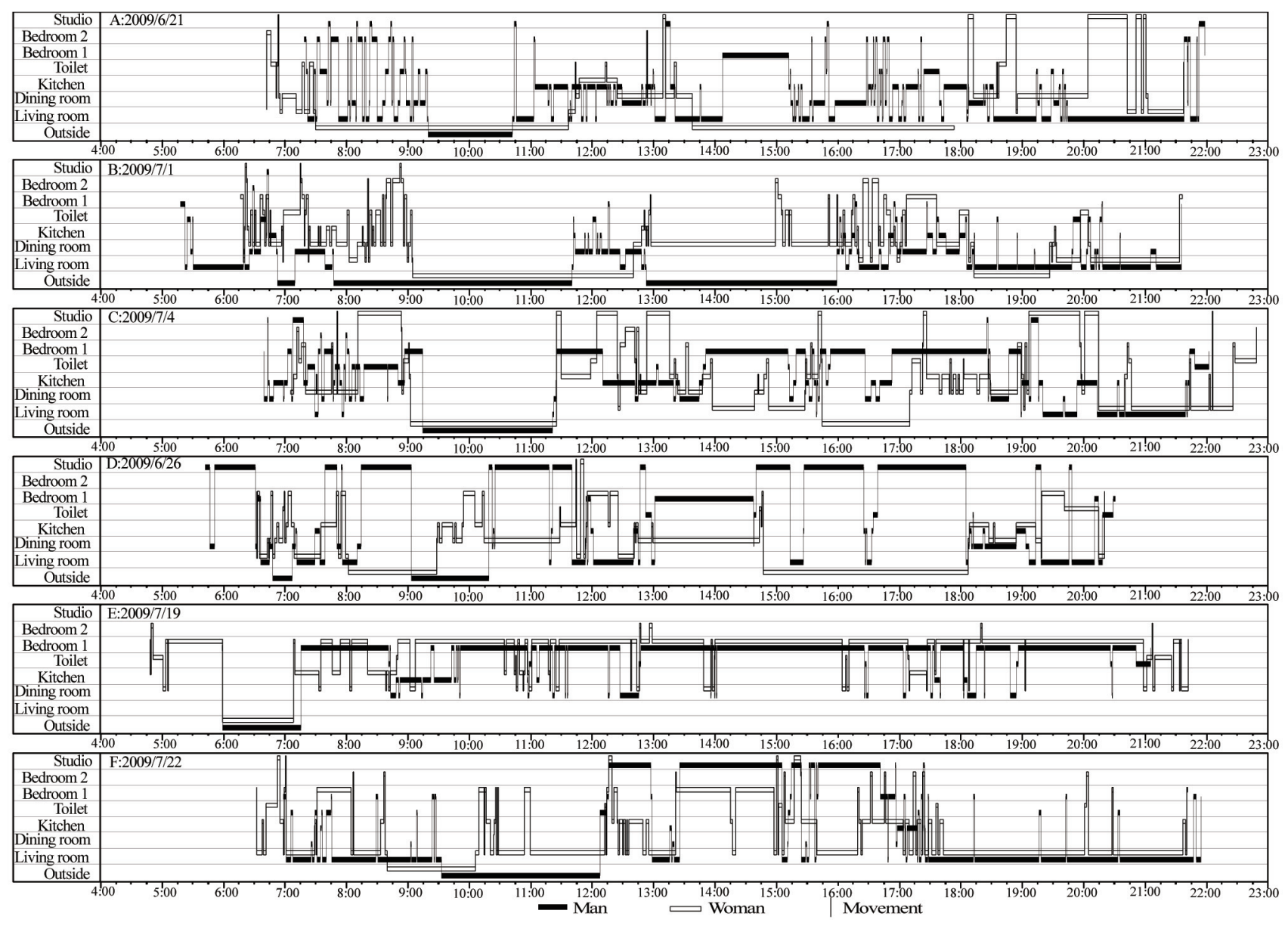

Fig.5. Staying Sequence in One Day for Each Elderly Couple 
Table 1.Total Staying Duration of the Elderly Couples

\begin{tabular}{|c|c|c|c|c|c|c|c|c|c|c|c|c|c|c|c|}
\hline & & \multicolumn{7}{|c|}{ Total staying duration of Man [min] (\%) } & \multicolumn{7}{|c|}{ Total staying duration of woman [min] (\%) } \\
\hline & & Living room & Dining room & Bedroom 1 & Bedroom 2 & Studio & Kitchen & Toilet & Living room & Dining room & Bedroom 1 & Bedroom 2 & Studio & Kitchen & Toilet \\
\hline \multirow{4}{*}{ 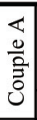 } & $\bar{M}$. & $115(18.6)$ & $298(48.2)^{*}$ & $0(0)$ & & $9(1.5)$ & $113(18.3)$ & $43(6.9)$ & $96(47.5)^{*}$ & $29(14.4)$ & $0(0)$ & & & & \\
\hline & A. & & $455(3$ & 169 & & & $137(10.8)$ & $76(6.0)$ & & $137(57.6)^{*}$ & & & & & \\
\hline & Evg. & $372(82.3)^{*}$ & $45(1$ & $0(0)$ & & $7(1.5)$ & & $9(2.0)$ & $423(66.3)^{*}$ & $130(20.4)$ & $0(0)$ & & & & \\
\hline & Sum & $857(36.6)^{*}$ & $798(3$ & & & $32(14)$ & & $128(5.5)$ & & & & & & & \\
\hline \multirow{4}{*}{ 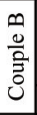 } & M. & & 200 & & & & & & & & & & & & \\
\hline & A. & 454( & & & & & & & & & & & & & \\
\hline & Evg. & 392( & & & & & & 37( & 312( & & & & & & \\
\hline & Sum & 973( & & & & & & & 376 & & & & & & \\
\hline \multirow{4}{*}{$\begin{array}{l}0 \\
0 \\
0 \\
0 \\
0\end{array}$} & M. & & & & & & & & & & & & & & \\
\hline & A. & & & & 114 & & 146 & & 229 & & & & 258 & 10 & \\
\hline & Evg. & 232( & & & & & & 290 & 234( & & & & & & \\
\hline & Sum & 290 & & & & 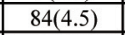 & 232 & 127 & 468 & & & & 474 & 26 & \\
\hline \multirow{4}{*}{$\begin{array}{l}0 \\
\frac{0}{0} \\
\vdots \\
\vdots\end{array}$} & M. & & & & & * & & & 180 & & & & & & \\
\hline & 1. & & & 261 & & $628(49.2)^{*}$ & 101 & 20( & 128 & 366 & & & & & \\
\hline & Evg. & 219 & & & & $29(9.0)$ & & & 190( & & & & & & \\
\hline & Sum & 682 & & & & $1370(48.3)^{*}$ & & $80(2.8)$ & $498(30.6)^{*}$ & 4921 & 309 & & $4(0.2)$ & 256 & .3) \\
\hline \multirow{4}{*}{ 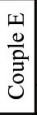 } & M. & & & 9) $)^{*}$ & $0(0)$ & & $88(14.7)$ & $5(0.9)$ & & .5) & $423(62.5)^{*}$ & $20(2.9)$ & $\rightarrow$ & 167 & \\
\hline & 1. & & & & & & $91(7.6)$ & $49(4.1)$ & & & $1095(86.8)^{*}$ & $12(0.9)$ & & 87 & \\
\hline & Evg. & 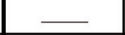 & & 340 & $(0.5)$ & 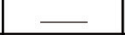 & $0(0)$ & $31(8.2)$ & . & & $389(82.4)^{*}$ & $3(0.6)$ & & & $.0)$ \\
\hline & Sum & $\bar{z}$ & 4.9) & $1797(82.8)^{*}$ & $3(0.1)$ & - & $179(8.3)$ & $85(3.9)$ & $\overline{-}$ & $5.5)$ & $1907(79.1)^{*}$ & $35(1.4)$ & & 2571 & $79(3.3)$ \\
\hline \multirow{4}{*}{ 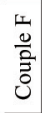 } & M. & $373(58.6)^{*}$ & & & $0(0)$ & $171(26.9)$ & 210 & $30(4.7)$ & $431(45.5)^{*}$ & $17(1.8)$ & $323(34.1)^{*}$ & $3(0.3)$ & $14(1.5)$ & 133 & \\
\hline & 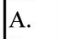 & $469(43.0)^{*}$ & $24(2.2)$ & & $5(0.4)$ & $463(42.4)^{*}$ & $37(3.4)$ & $28(2.6)$ & $476(41.6)^{*}$ & $6(0.5)$ & $347(30.3)$ & $24(2.1)$ & $15(1.3)$ & 257( & \\
\hline & Evg. & $377(92.0)^{*}$ & & & $0(0)$ & $0(0)$ & & $20(4.9)$ & $425(80.0)^{*}$ & $1(0.2)$ & $41(7.7)$ & $2(0.4)$ & $10(1.9)$ & $26(4.9)$ & $26(4.9)$ \\
\hline & Sum & $1219(57.1)^{*}$ & $43(2.0)$ & $93(4.3)$ & $5(0.2)$ & $634(29.7)$ & $65(3.0)$ & $78(3.7)$ & $1332(50.7) *$ & $24(0.9)$ & $711(27.1)$ & $29(1.1)$ & $39(1.5)$ & $416(15.9)$ & $74(2.8)$ \\
\hline
\end{tabular}

was calculated as below:

$$
\mathrm{T}=\frac{\mathrm{T}_{e, r, p}}{\sum_{\mathrm{r}}^{\mathrm{R}} \mathrm{T}_{\mathrm{e}, \mathrm{r}, \mathrm{p}}} \times 100 \% \ldots(1) \quad \mathrm{Sum}=\frac{\sum_{\mathrm{p}}^{\mathrm{P}} \mathrm{T}_{\mathrm{e}, \mathrm{r}, \mathrm{p}}}{\sum_{\mathrm{r}}^{\mathrm{R}} \sum_{\mathrm{p}}^{\mathrm{p}} \mathrm{T}_{\mathrm{e}, \mathrm{r}, \mathrm{p}}} \times 100 \% \ldots
$$

Te,r,p: Total staying duration of a given person in a given room in a given period in the whole investigation period (3-4 days)

e: Subject $=($ man in couple A, woman in couple A, ... woman in couple F $)$

$\mathbf{r}:$ Room $=($ living room,$\ldots$ kitchen $)$

p: Period in a day $=$ (morning, afternoon, evening $)$

R: Total number of rooms

P: Total number of periods in a day

Although the authors could have just appointed the room with the highest $\mathrm{T}$ as the Base in the period, there were also some cases where there was very little difference between the second highest $\mathrm{T}$ and the highest one. Thus, the authors set several intervals according to the relative ratio for a given number of factors and appointed all the $\operatorname{room}(\mathrm{s})$ with $\mathrm{T}$ in the highest interval as Bases. For example, if a house had $\mathrm{n}$ rooms when the proportion of staying duration was $100 / \mathrm{n}$ in each room, it meant that the resident spent the same amount of time in each room. When the staying duration in one room was more than $100 / \mathrm{n}$, it meant that the resident spent more time in this room than in at least one other room. In this way, the proportion (\%) was divided into $\mathrm{n}$ intervals as below:

(1) $[0,100 / \mathrm{n}]$ : Resident spent relatively little time in this room.

(2) $[100 / n, 100 /(n-1)]:$ resident spent more time in this room than in at least one other room.

(n) $[100 / 2,100]$ : resident spent the most amount of time in this room.

Thus, the authors determined the Base (Bases) of certain residents in certain rooms during certain periods and during the whole day (Table 1.).

2) Classification of subject couples by the room chosen as Base

I. Base choice centered on bedroom: The couple always took the bedroom as Base in any period (couple E).

II. Base choice centered on living room in the evening and separate rooms during the day: Both the man and woman of the couple took the living room as Base in the evening, but they might have chosen Base in different rooms during the day (couples A, B, $\mathrm{C}, \mathrm{D}$, and F)

\section{3) Differences between men and women in Base} choice

During the course of the whole day, the average woman had more Bases (1.3 per person) than the average man (1.2 per person). This tendency was more apparent in the morning, when the average woman had more Bases (1.7 per person) than the average man (1 per person) (Table 2.). Moreover, in the morning, the proportion of the total staying duration of the elderly women in the Base was much lower than that of the

Table 2. Average Number of Base per Person

\begin{tabular}{c|cccc}
\hline & Morning & Afternoon & Evening & Whole day \\
\hline Man & 1.0 & 1.2 & 1.0 & 1.2 \\
Woman & 1.7 & 1.2 & 1.0 & 1.3 \\
\hline
\end{tabular}

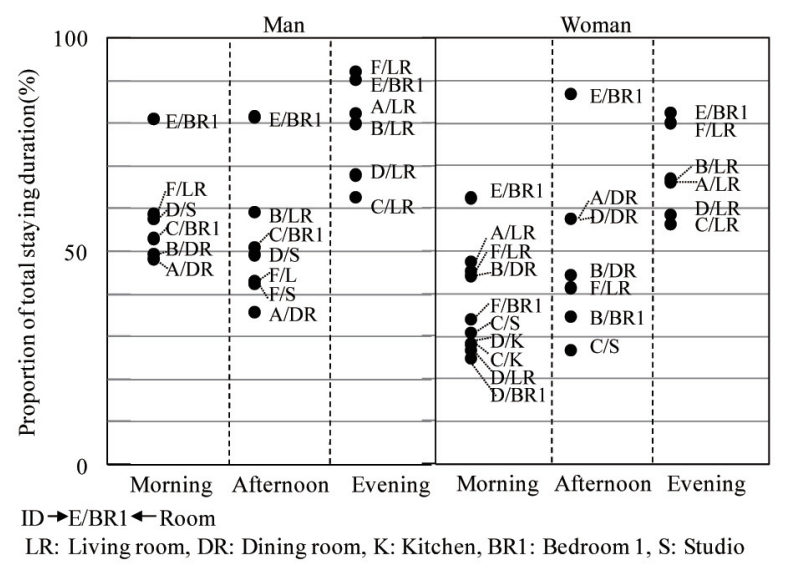

Fig.6. Proportion of the Total Staying Duration in the Respective Bases of the Elderly Men and Women in each Period 
elderly men (Fig.6.). This observation suggests that the elderly women used more rooms in the morning. There were two cases in which the women took the kitchen as Base in the morning, but none of the elderly men did so.

4) Difference between Bases obtained by objective observation and those Bases identified by subjects

The Base obtained by calculating the proportion of the total staying duration (Objective Base) was compared with the Base identified by the elderly couple (Subjective Base). For example, when the Objective Bases of a particular subject were the living and dining rooms, but the Subjective Base that he/ she identified was only the living room, the authors marked "Accord" on the living room where Objective and Subjective Bases accord, and "Disaccord" on the dining room, which had been ignored by the subject. Then the number of Accords and Disaccords was counted and ratio of Accord $(\mathrm{Ra})$ was calculated by the following formula:

$$
\begin{aligned}
& \mathrm{Ra}=\frac{\mathrm{N}_{\text {accord }}}{\mathrm{N}_{\text {accord }}+\mathrm{N}_{\text {disaccord }}} \times 100 \% \ldots \text { (3) } \\
& \text { Ra: Ratio of Accord "Accord" } \\
& \mathbf{N}_{\text {accord }}: \text { Number of "Acor } \\
& \mathbf{N}_{\text {disaccord }}: \text { Number of "Disaccord" }
\end{aligned}
$$

Because most respondents could not clearly identify the room they had spent the most time in for each period in the interview, the authors only have a Subjective Base for the whole day. However, the authors also compared the Objective Base in each period with the Subjective Base for the whole day to clarify in which period they accord more.

The results showed that the Objective and Subjective Bases were more often the same for the men ( $\mathrm{Ra}$ : $85.7 \%$ ) than the women (Ra: $37.5 \%$ ). The Objective and Subjective Bases in accord were less in the evening in the cases of both the men and women. This shows that the Base in the mind of the subjects indicated the room where they spent the most time during the day, although most of them spent most of the evening in the living room.

The Ra of the elderly men was high both in the morning $(83.3 \%)$ and afternoon $(85.7 \%)$, possibly because most elderly men stayed in the same room during the day, so it was easy for them to identify their
Base. The Ra of the women was low in the morning $(40.0 \%)$, possibly because the women used multiple rooms in the morning, their Base for that period was not as clear to them as to the men. In the afternoon, the women had fewer Bases and spent more time in a specific Base, so it became easier for them to identify the Base (Ra: 71.4\%) (Table 3.).

\section{5) Spatial conditions of the Base in each period}

During the day, though more subjects chose a Base facing south, there were others who chose a room facing north or even a windowless room. The authors asked these subjects why they spent so much time in a room with an orientation that is not ideal, and they answered that it was because it was cooler there (Table 4.).

Table 4. Number of the Orientation of Base

\begin{tabular}{c|c|c|c|c|c|c}
\hline & Dark & East & North & North, east & South & Sum \\
\hline Morning & 3 & 1 & 4 & 2 & 6 & 16 \\
Afternoon & 4 & 0 & 2 & 2 & 6 & 14 \\
Evening & 0 & 0 & 0 & 2 & 10 & 12 \\
\hline
\end{tabular}

Dark: there is no window directly facing outside

The surveyed couples in Tangshan did not like to stay in an air-conditioned environment. Even if there was an air conditioner in the living room or bedroom, they seldom used it unless there was a guest. During the day, they preferred north-facing or windowless rooms, but in the evening, when it got cool, they gathered in the living room.

\subsection{Base-choosing and room-use manner}

Although the authors knew how a certain subject allocated his/her time in each room, the authors were still interested in which rooms the couples used together and when. In order to clarify this, the roomuse manner was classified into three types:

(1) Used alone by man: Only the man stayed in the room. (2) Used alone by woman: Only the woman stayed in the room.

(3) Sharing: The couple stayed in the room at the same time. Then, the proportion of each room-use manner (U) was calculated as below:

$$
\mathrm{U}=\frac{\mathrm{T}_{\mathrm{w}, \mathrm{r}, \mathrm{p}}}{\sum_{\mathrm{w}}^{\mathrm{W}} \mathrm{T}_{\mathrm{w}, \mathrm{r}, \mathrm{p}}} \times 100 \%
$$

Tw,r,p: Total staying duration of a given room-use manner in a given

\begin{tabular}{|c|c|c|c|c|c|c|c|c|c|c|}
\hline \multirow{3}{*}{ ID } & \multicolumn{5}{|c|}{ Man } & \multicolumn{5}{|c|}{ Woman } \\
\hline & \multirow{2}{*}{$\begin{array}{l}\text { Subjectvie } \\
\text { Base }\end{array}$} & \multicolumn{4}{|c|}{ Objectvie Base in each period and the whole day } & \multirow{2}{*}{$\begin{array}{l}\text { Subjectvie } \\
\text { Base }\end{array}$} & \multicolumn{4}{|c|}{ Objectvie Base in each period and the whole day } \\
\hline & & Morning & Afternoon & Evening & Whole day & & Morning & Afternoon & Evening & Whole day \\
\hline $\mathrm{A}$ & Dining room & Dining room* & Dining room* & Living room & $\begin{array}{c}\text { Living room, } \\
\text { Dining }\end{array}$ & Dining room & Living room & Dining room* & Living room & Living room \\
\hline B & Living room & Dining room & Living room* & Living room* & Living room* & Bedroom 1 & Dining room & $\begin{array}{l}\text { Dining room, } \\
\text { Bedroom } 1 *\end{array}$ & Living room & Dining room \\
\hline $\mathrm{C}$ & Bedroom 1 & Bedroom 1* & Bedroom 1* & Living room & Bedroom 1* & Studio & Studio*, Kitchen & Studio* & Living room & Living room, Studio* \\
\hline $\mathrm{D}$ & Studio & Studio* & Studio* & Living room & Studio* & Bedroom 1 & $\begin{array}{c}\text { Living room, } \\
\text { Bedroom } 1^{*}, \text { Kitchen }\end{array}$ & Dining room & Living room & $\begin{array}{l}\text { Living room, } \\
\text { Dining room }\end{array}$ \\
\hline $\mathrm{E}$ & Bedroom 1 & Bedroom 1* & Bedroom 1* & Bedroom 1* & Bedroom 1* & Bedroom 1 & Bedroom 1* & Bedroom 1* & Bedroom 1* & Bedroom 1* \\
\hline \multirow[t]{3}{*}{$\mathrm{F}$} & Living room & Living room* & $\begin{array}{c}\text { Living room*, } \\
\text { Studio }\end{array}$ & Living room* & Living room* & Living room & $\begin{array}{c}\text { Living room*, } \\
\text { Bedroom } 1\end{array}$ & Living room* & Living room* & Living room* \\
\hline & $\mathrm{N}_{\text {accord }}$ & 5 & 6 & 3 & 6 & $\mathrm{~N}_{\text {accord }}$ & 4 & 5 & 2 & 3 \\
\hline & Accuracy (\%) & 83.3 & 85.7 & 50.0 & 85.7 & Accuracy (\%) & 40.0 & 71.4 & 33.3 & 37.5 \\
\hline
\end{tabular}
room in given period in the whole investigation period (3-4 days) w: Room-use manner $=($ Used alone by man, Used alone by woman, Sharing $)$ W: Total number of room-use manner

Table 3. Number of Times that the Objective and Subjective Bases Are and Are Not in Accord 
Table 5. Room-Use Manner for Each Room

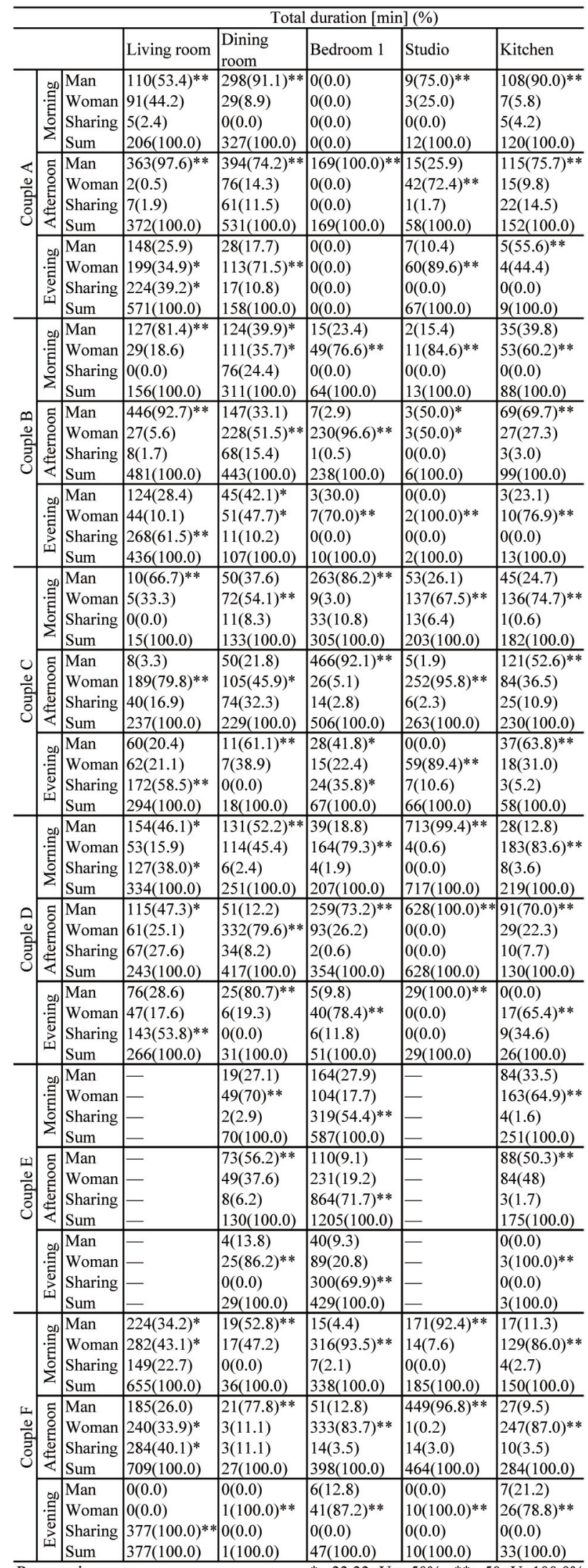

Room-using way:

Man: Used alone by man, Woman: Used alone by woman, Sharing: Sharing

r: Room $=($ living room,$\ldots$ kitchen $)$

Toilet and bedroom 2 that were hardly shared were excluded.

p: Period in a day $=$ (morning, afternoon, evening $)$

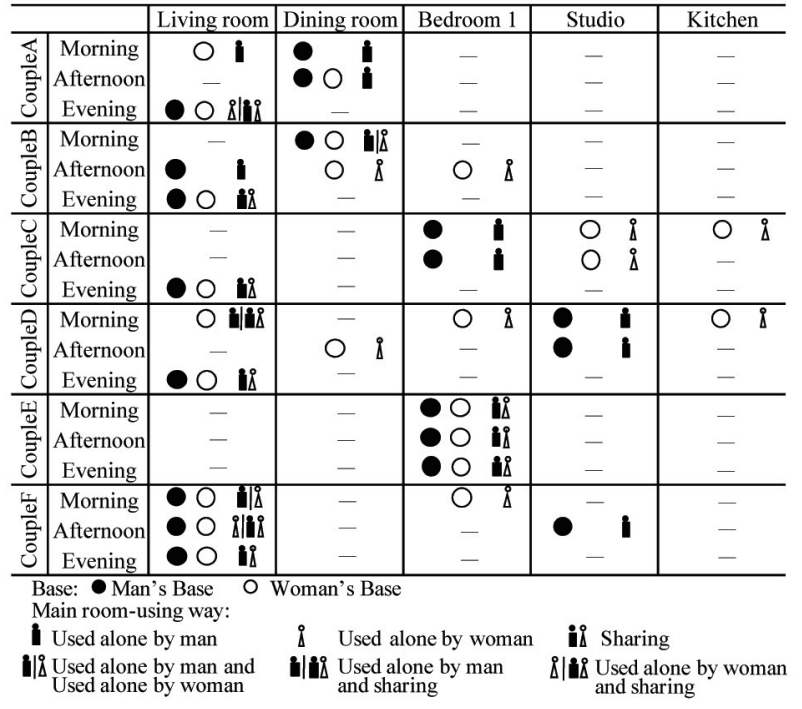

Fig.7. Room-Use Manner in the Base

For a certain room during a certain period, if there was only one room used with $\mathrm{U}>50 \%$, or $33.33<\mathrm{U} \leq$ $50 \%$, it was specified as the main room-use manner. If there were two rooms used with $33.33<\mathrm{U} \leq 50 \%$, they were both specified as main room-use manners. For example, for couple A in Table 5., in the morning, the main room-use manner of the living room was (1), and in the evening, the main room uses of the living room were (2) and (3) .

According to Fig.7., most couples (except for couple E) were inclined to have the living room as the same Base and share the Base in the evening. They tended to take different rooms as Base and use the room alone during the day. Even if both the man and woman in the couple took one room as Base, they were inclined to use it at different times rather than sharing it (3 out of 5 cases).

\section{Conclusions}

This study clarified the room in which elderly Chinese couples stay for the longest duration between rising and going to bed (Base). The findings are as follows:

1) The elderly men tended to stay in one room during the day, but the elderly women used multiple rooms, especially in the morning. Some elderly women used the kitchen as Base in the morning, but none of the elderly men had such use for it.

2) The Objective and Subjective Bases were more in accord during the day. This shows that the Base in the subjects' minds indicated the room where they spent the most time during the day. The Objective and Subjective Bases were more in accord among the men than the women.

3) In summer, they also chose a north-facing or windowless room as Base. Additional interviews revealed that this choice was made because such rooms were cooler. 
4) The subject couples fell into two types: i.) This type always took the bedroom as Base and shared it in any given period, and ii.) This type tended to use the living room as the same Base and share it in the evening. They were inclined to take different rooms as Base and use them alone during the day. Even if both the man and woman of the couple took one room as Base, they were inclined to use it alone at different times rather than share it.

Based on these findings, our suggestions for the layout plan of a dwelling unit for elderly couples are as follows:

1) The layout of a dwelling is more important for elderly women. Rooms relating to housework (such as the kitchen and toilet) should be close to the elderly women's morning Base.

2) When designing living spaces for elderly couples type i.), the dwelling should have one large room with good orientation (facing south). For type ii.) couples, it is important to ensure a correct number of rooms. In addition to a shared living room, there should be at least another room to ensure that each individual can have his/her own space. In some cases, they need one more room, like a studio. The size of the other rooms is not so important, because the elderly couple seldom use them together. It is not necessary that all the rooms face south, because in summer, some elderly subjects preferred rooms that were north facing or windowless, for it is cooler there.

\section{Acknowledgements}

The authors appreciate the cooperation of the six subject couples. This work is supported by KAKENHI (19686036).

\section{Notes}

Different from the international definition of the aged, the government of China considers citizens over 60 as aged, according to the Law of the People's Republic of China on Protection of the Rights and Interests of the Elderly: Article 2. The aged mentioned in this Law refer to citizens over 60.

Suggestions on adjusting housing structure and stabilizing housing prices. Ministry of Housing and Urban-Rural Development of the P.R. China, 2006.5.

Tangshan is an industrial city in Hebei province, located southeast of Beijing. The area is $13,472 \mathrm{~km}^{2}$, and the population is 7.35 million (as of 2009.6).

4 After minute-by-minute filtering, the missing values needed to be filled in the data. Though the Active RFID Tag sent a signal every second, sometimes the Active RFID Reader failed to receive

\begin{tabular}{|c|c|c|c|c|}
\hline Date and time & \multicolumn{2}{|c|}{ Staying } & Moving times & If keeping flat \\
\hline $2009 / 6 / 2611: 20$ & \multicolumn{2}{|c|}{ Living room } & 6 & No \\
\hline $2009 / 6 / 2611: 21$ & \multicolumn{2}{|c|}{ Living room } & 3 & No \\
\hline $2009 / 6 / 2611: 22$ & \multicolumn{2}{|c|}{ Living room } & 0 & No \\
\hline $2009 / 6 / 2611: 23$ & \multicolumn{2}{|r|}{ Living room } & $\mathrm{m}$ & No \\
\hline $2009 / 6 / 2611: 24$ & \multicolumn{2}{|c|}{ Living room } & 5 & No \\
\hline $2009 / 6 / 2611: 25$ & \multicolumn{2}{|r|}{ Living room } & $\mathrm{m}$ & No \\
\hline $2009 / 6 / 2611: 26$ & \multicolumn{2}{|c|}{ Living room } & 9 & No \\
\hline $2009 / 6 / 2611: 27$ & & Out & 0 & Yes \\
\hline $2009 / 6 / 2611: 28$ & 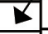 & Out & 0 & Yes \\
\hline $2009 / 6 / 2611: 29$ & & Out & 3 & Yes \\
\hline
\end{tabular}

Fig.8. Complete the Missing Values the signal when the Active RFID Tag was stable. Therefore, the authors needed to judge whether this was because the resident was simply in a stable position, although wearing the tags, or had taken them off and forgotten to record why he/she had done so. The acceleration data helped us ascertain this and complete the missing information. (Fig.8.)

\section{References}

1) Cao, W., Nagasawa, Y., and Yamashita, T. (1996) Living patterns of elderly in mid-rise walk-up apartment dwellings complexes in Tianjin: A study on dwellings planning for the urban elderly in China, Journal of Architecture and Planning, AIJ, No. 490, pp.73-81.

2) Enta, A., Hayashida, K., and Watanabe, H. (2008) Tracing of human walk by using slipper-type RFID Reader. Journal of Architecture and Planning, AIJ, No. 630, pp.1847-1852.

3) Kataoka, M., Suzuki, Y., and Nakatake, H. (1994) On recognizing the existence of dwelling base and relating to rooms in the house: A study on the base in dwellings for old age, Part 1, Journal of Architecture and Planning, AIJ, No. 460, pp.71-80.

4) Koga, T. and Takahashi, T. (1997) A discussion on "Jouza" in house of the single elderly: A study on appropriation of places in the house for the elderly-1, Journal of Architecture and Planning, AIJ, No. 494, pp.97-104.

5) Li, Z., Munemoto, J., Yoshida, Tetsu. and Tang, P. (2008) A study on behaviors along waterside using GPS: Walking test along water facilities in Chinese residential quarter, Journal of Architecture and Planning, AIJ, No. 630, pp.1665-1673.

6) Lin, W., Nishimura, S. Y., Takahashi, Y., Noguchi, T., Lu, W., Tsukidate, T., Morishita, M., and Zhou, Bo. (2006) The living style of elderly couples in collective housing in Da-lian and Harbin, China: A study on the planning of living spaces for elderly living in urban areas. Journal of Architecture and Planning, AIJ, No. 599, pp.1-7.

7) Masunaga, T., Yonehara, K., and Togashi, S. (2002) A study on home activities by the single aged living in housing units rented by UDC, Journal of Architecture and Planning, AIJ, No. 551, pp.259-265.

8) Matsuoka, K. (2002) Personal supporting system for daily life by monitoring human behaviors in a house (special issue on digital human: measurement and modeling of human functions), Systems, Control and Information, Vol. 46, No. 8, pp.484-489.

9) Mori, T. (2005) Behavior accumulation and pattern discovery in sensing room, IEICE technical report, artificial intelligence and knowledge-based processing, Vol.105, No. 224, pp.41-44.

10) Nakazono, M., Ooba, T., and Sasaki, T. (2006) Lifestyle of aged households before housing renovation of two room and one kitchen type of housing unit: A research on the renovation of existent public housing for aged households, Part 1, Journal of Architecture and Planning, AIJ, No. 609, pp.107-114.

11) Qu, X., Matsushita, D., and Munemoto, J. (2008) Study on roomusing behavior of elderly living alone in detached house sensing by Active RFID, Proceedings of the thirty-first symposium on computer technology of information, systems and applications, Tokyo, AIJ, pp.183-186.

12) Sawachi, T. and Matsuo, Y. (1989) Daily cycles of activities in dwellings in the case of housewives: Study on residents' behavior contributing to formation of indoor climate, Part 2. Journal of Architecture and Planning, AIJ, No. 398, pp.35-46.

13) Sawada, T. (2001) The Characteristics life style and way of living for the elderly and the aged people: Designing dwellings to support and enrich longevity lives, Part 1. Journal of Architecture and Planning, AIJ, No.547, pp.95-102.

14) Tapia, E. M., Intille, S. S., and Larson, K. (2004) Activity recognition in the home using simple and ubiquitous sensors, in the Proceedings of PERVASIVE 2004, vol. LNCS 3001, Heidelberg Berlin, pp.158-175. 